Available online at http://iddtonline.info

$$
\text { REVIEW ARTICLE }
$$

\title{
A REVIEW UPDATED ON ETHNOPHARMACOLOGICAL PROFILE OF KIRGANELIA RETICULATA POIR (BAILL). : AN IMPORTANT HERBAL PLANT
}

\author{
Rajesh Kumar Soni ${ }^{* 1}$, Vihangesh Dixit ${ }^{1}$, Harsh Singh $^{2}$, Raghuveer Irchhaiya ${ }^{1}$, Prayag Yadav $^{1}$ \\ ${ }^{I}$ Institute of Pharmacy, Department of Pharmacognosy, Bundelkhand University, Jhansi, (U.P), India \\ ${ }^{2}$ Plant Diversity, Systematics \& Herbarium Division, CSIR-National Botanical Research Institute, Lucknow, U.P, India \\ *Corresponding Author's Email: rajeshsoni1987@gmail.com, Tel: +918756696949, +918737001776
}

\begin{abstract}
Kirganelia reticulata (Poir.) Baill. is known for its importance in various traditional medicines around the world. In present review covers a literature survey across from 1971 to 2014 until now. The some information collected from published literature on species of Kirganelia reticulata (Poir.) Baill. (=Syn. Phyllanthus reticulatus Poir.).The extract and the compounds isolated from Kirganelia reticulata show a wide spectrum of biological activities including antidiabetic, antibacterial, antioxidant, hepatoprotective, antiplasmodial, anticiceptive, analgesic and anti-inflammatory properties.
\end{abstract}

Keywords: Kirganelia reticulata (Poir) Baill, Ethnopharmacological properties.

\section{INTRODUCTION}

Herbal drugs play an important role in the healthcare programs. Ancient literature incorporates a remarkable broad definition of medicinal plants and considers all parts of the plant to be potential source of medicinal substances. The main hindrance in the acceptance of herbal medicines is the lack of documentation and quality control. So it becomes extremely important to make an effort towards standardization of the plant material to be used as medicine ${ }^{\mathbf{1}}$. India is a varietal emporium of the medicinal and aromatic plants (MAPs) and we have well-established local healthcare tradition still relevant in indigenous healthcare system. As per World Health Organisation (WHO) estimates, almost $80 \%$ of the population of developing countries relies on traditional medicines, mostly plant drugs, for their primary health care needs. In developed countries, the use of Indian traditional medicines is quite prevalent and also, modern pharmacopoeia still contains at least $25 \%$ drugs derived from plants. The use of medicinal plants in the Indian subcontinent can be traced back to the Vedic period. The texts mentioning the uses of different medicinal plants are the Rigveda (written between 4500 and $1600 \mathrm{BC})$, the Atharveda (2000-1000 BC), the Charaka Samhita ( 900 BC) and the Sushruta Samhita $\left(\sim 600\right.$ BC); these texts are written in Sanskrit ${ }^{2}$.

Kirganelia reticulata (Poir) Baill. is belonging to the family Euphorbiaceae, popularly known as "potato plant or potato bush" and are variously named in different parts of the world. Synonymously, it is also named as Phyllanthus reticulatus Poir. and commonly used in Indian Ayurvedic system of medicine in various ailments related to liver, kidney, genitourinary system and stomach. It has properties of Rasa (Kashaya, Tikta, Madhura, Guna (Lakhu) and Veerya (Seeta). The Ayurvedic literature has shown its wide utilization as in Vata, Pitta, diabetes, burning sensation, burns, skin diseases, obesity and urinary retention, skin eruption. The use of this drug is now gaining momentum because of its novel antiviral activity against Hepatitis B virus and for several other biological activities such as hypotensive effects viral infections; hepatotoxicity causing liver diseases and jaundice ${ }^{3}$. Some plant images are given in Figure No. 1.

\section{ETHNOPHARMACOLOGICAL PROPERTIES}

In ethnopharmacological activity survey on worldwide generally seen that different country gives different activity such as In Tanzania, the parts of leaves extract with water and methanol gives various activity ${ }^{\mathbf{4 , 5}}$. And also root extract and entire plant extracts gives antifungal and in vitro Hypotensive activity ${ }^{\mathbf{5 , 6 , 7}}$. In Thailand, dried roots of $K$. reticulata against many bacterial species gives no irritant or tumor-promoting activity found (Hecker, personal communcitation) ${ }^{\mathbf{8}}$. In Indonesia: West Sumatra. Leaves give negative test for alkaloids?. Generally known to contain terpenoids betulinic acid and friedelin ${ }^{10}$. In India, Uttar Pradesh: Lucknow, extracts of the above ground part of the plants give hypotensive activity in vivo of $\mathrm{dog}$ and also give antispasmodic activity ${ }^{11}$. These are described as following:

\section{Antidiabetic activity, Anti- hyperglycaemic and hypoglycaemic activities}

The plant $K$. reticulata is claimed to have antidiabetic activity in tribal area. To validate the tribal claim, the petroleum ether and ethanolic extracts of leaves of the $K$. reticulata were orally tested at 500 and $1000 \mathrm{mg} / \mathrm{kg}$ for hypoglycaemic effect in alloxan induces diabetic mice. It shows antidiabetic activity at the dose of $1000 \mathrm{mg} / \mathrm{kg}$. The phytochemical screening of the residues revealed the presence of terpenoids glycosides, protein, carbohydrates and absence of alkaloids and steroids ${ }^{12,13,14}$. 


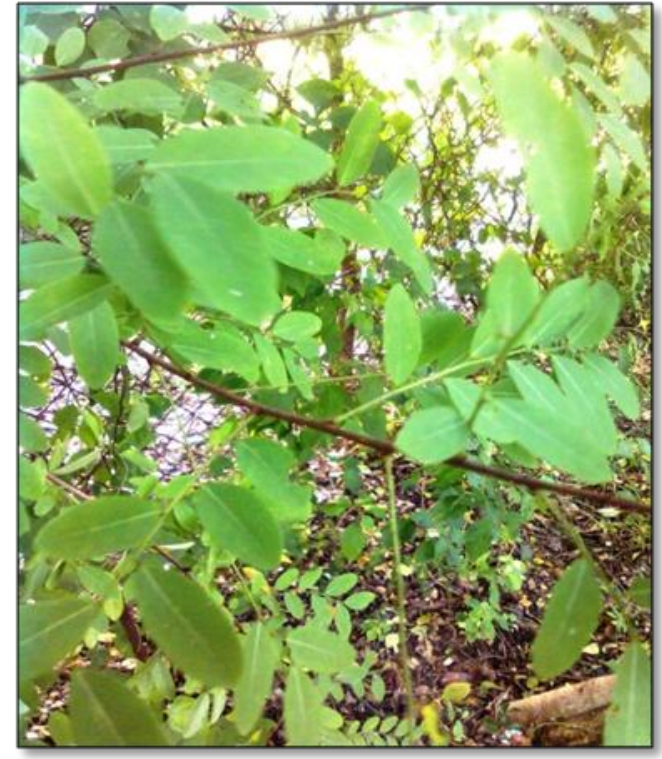

(A)

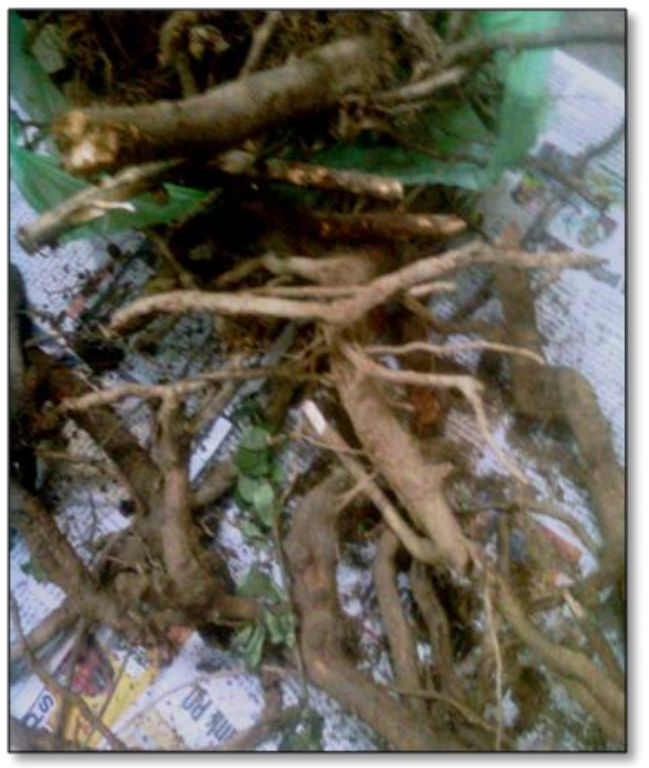

(C)

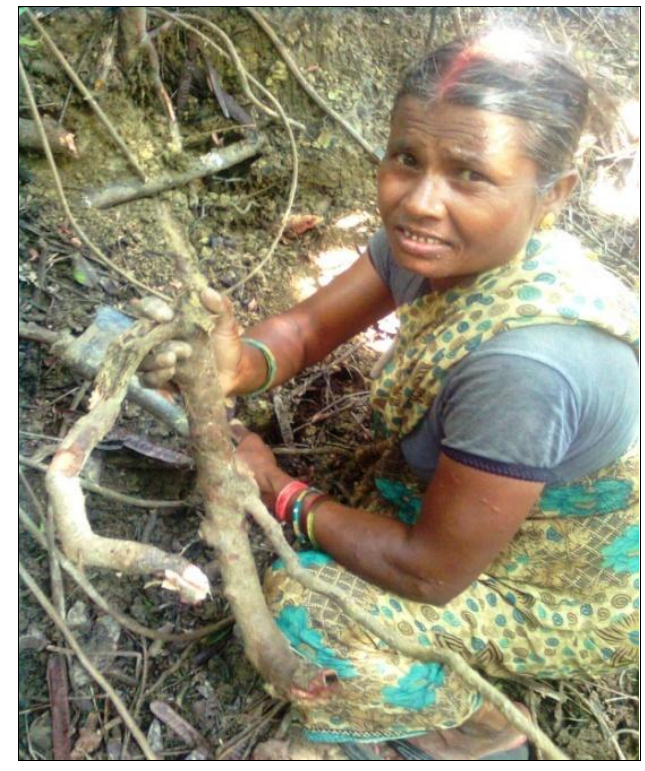

(B)

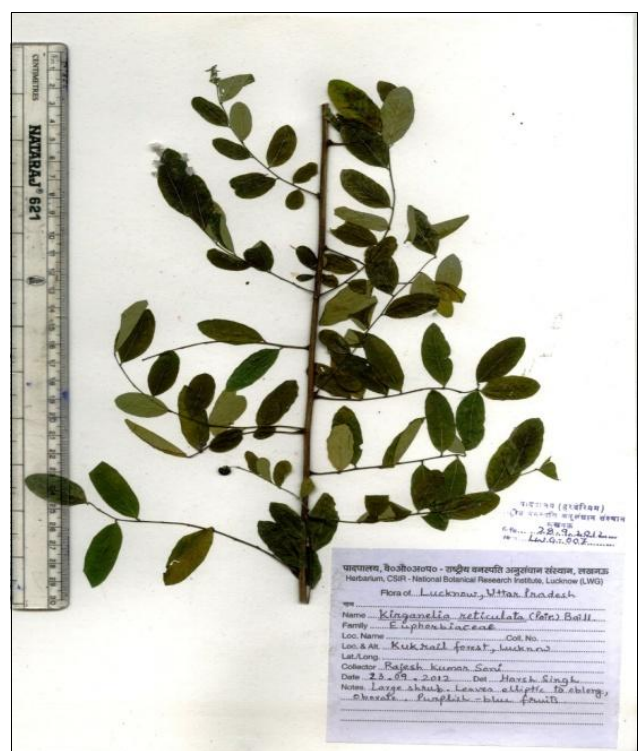

(D)

Figure 1 (A): Showing plant, (B): Showing cutting of root part, (C): Showing collection of root part \& (D): Showing authentication of plant.

\section{Antibacterial activities}

The in vitro antibacterial activities of leaf extract (Methanol and Ethanol) from 10 genus species. Which are medicinally important, were investigated by agarwell diffusion method against four food borne human pathogens (Staphylococcus aurous, Salmonella typhi, Vibrio cholera and Pseudomonas aeruginosa). Leaf extracts contained high level of phenols and exhibit differential antibacterial activity against all four tested human pathogenic bacteria. The phenolic constituents of the tested extracts are closely associated with antibacterial activity. Highest antibacterial activity is exhibited by $K$. reticulata and can be used as a promising source of antibacterial $\operatorname{drug}^{15}$; methanol, chloroform and hexane extracts from leaves of $K$. reticulata, used in Indian Ayurvedic Medicine for the treatment of several ailments of microbial and non-microbial origin were evaluated for potential antibacterial activity against methicillin isolated from clinical specimen was studied. The minimum inhibitory concentration (MIC) and minimum bactericidal concentration (MBC) resistant Staphylococcus aureus (MRSA). Antibacterial activity and biofilm production of crude extracts against MRSA (ATCC 25923) values of the methanol, chloroform and hexane extracts were in the range of 12.5 to $50.0 \mathrm{mg} / \mathrm{ml}$ and 25.0 to $100.0 \mathrm{mg} / \mathrm{ml}$, respectively. Amongst the evaluated extracts, the methanolic extract showed the strongest antibacterial effect as well as biofilm inhibition. Micro plate screening used for detection of biofilm formation by Staphylococci is a quantitative model to study its adherence level and has been a sensitive method ${ }^{\mathbf{1 6}}$; and the in vitro antibacterial activity 
of crude methanolic, chloroform and hexane extracts of the leaves of $K$. reticulata were investigated. Susceptibility of some Gram-negative organisms (Escherichia coli, Pseudomonas aeruginosa and Salmonella typhi) and Gram-positive organism (Staphylococcus aureus) were tested. Agar well diffusion and broth dilution methods were used to determine the minimum antibacterial activity against all the tested microorganisms. The extracts exhibited antibacterial activities with zones of inhibition ranging from 9.07$30.10 \mathrm{~mm}, 8.17-24.57 \mathrm{~mm}$ and $5.60-14.67 \mathrm{~mm}$ for methanol, chloroform and hexane extracts respectively. Screening of crude extracts showed notable minimum inhibitory concentration (MIC) and minimum bactericidal concentration (MBC) at concentrations of 100 to $6.25 \mathrm{mgml}^{-1}$. The organisms were more sensitive to the methanolic extract of the leaves, where as extracts from other solvents like chloroform and hexane showed moderate to weak activity respectively. Similar results have been showed in MIC and MBC ${ }^{17}$.

\section{Antioxidants activities and Free radical scavenging}

Antioxidant activity of entire plant of $K$. reticulata by performing different in vitro antioxidant assays, including 2,2-Diphenyl-1- Picrylhydrazyl (DPPH) radical scavenging, beta-carotene bleaching, superoxide anion radical scavenging, reducing power and metal chelating assay at different concentrations (100, 200 and $400 \mu \mathrm{g} / \mathrm{ml})$. The entire plant powder of $K$. reticulata shows good antioxidant activity of about $90.0 \%$ when compared with standard butylated Hydroxy Toluene (BHT) $(85 \%)$ at a concentration of $400 \mu \mathrm{g} / \mathrm{ml}$. Results obtained reveal that methanolic extracts of entire plant of $K$. reticulata tapossess higher antioxidant activity when compared when compared with ethanolic extract. Thus, this study suggests that $K$. reticulata plant can be used as a potent source of nature antioxidants ${ }^{18}$; Free radicals are implicated for many diseases including Diabetes mellitus, arthritis, cancer, ageing. etc. In treatment of these diseases, antioxidant therapy has gained utmost importance. $K$. reticulata popularly important medicinal plant. Keeping in view of the cited activity, it is contemplated to screen the plant for in vitro antioxidant activity using different models viz. DPPH radical scavenging, ABTS radical scavenging, iron chelating activity and lipid peroxidation assay, nitric oxide scavenging assay, alkaline DMSO assay, total antioxidant capacity and non- enzymatic haemoglobin glycosylation assay. The results were analyzed statistically by regression method. Its antioxidant activity was estimated by IC50 value and the values are 20.36 $\mu \mathrm{g} / \mathrm{ml}$ (DPPH radical scavenging), $42.59 \mu \mathrm{g} / \mathrm{ml}$ (ABTS radical scavenging), $32 \mu \mathrm{g} / \mathrm{ml}$ (Iron chelating activity) and $41.91 \mu \mathrm{g} / \mathrm{ml}$ (lipid peroxidation), $122.8 \mu \mathrm{g} / \mathrm{ml}$ (nitric oxide scavenging) and $2.57 \mu \mathrm{g} / \mathrm{ml}$ (alkaline DMSO). In total antioxidant capacity assay, $1 \mathrm{mg}$ of extract is equivalent to $51 \mu \mathrm{g}$ of ascorbic acid. It showed $66.64 \%$ inhibition of haemoglobin glycosylation. In all the testing, a significant correlation existed between concentrations of the extract and percentage inhibition of free radicals, metal chelation or inhibition of lipid peroxidation. The antioxidant property may be related to the polyphenols and flavonoids present in the extract.
These results clearly indicate that $K$. reticulata is effective against free radical mediated diseases ${ }^{\mathbf{1 9}}$; antioxidant properties of the medicinal plant $K$. reticulata. The different solvent extracts of $K$. reticulata leaves were screened for their in vitro phytochemical and antioxidant activity. Leaves were extracted with solvents of different polarities like aqueous, ethanol, methanol, chloroform, acetone and hexane. The distributions of the main active principles such as alkaloid, flavonoids, phenols, steroids tannins etc. present in the plant were analyzed. It was also focused to determine the total phenolic and flavonoid content present in the extracts. Extracts showed promising results for total antioxidant capacity and reductive capability when compared with standard drug. The ethanol extract was found to possess excellent phytochemical and antioxidant activities. The antioxidant property may be attributed to the presence of flavonoids and phenolics present in the drug. The ability of the crude extracts of $K$. reticulata towards reduction, presence of phenol, flavonoid and antioxidant is an indication of its broad spectrum potential which may be employed in the management of various diseases ${ }^{20}$. Many plants possess antioxidant ingredients that provided efficacy by additive or synergistic activities. Antioxidant activity of the methanol crude extract of entire plant of $K$. reticulata was assessed using DPPH, superoxide anion and metal chelating assays at different concentrations. The potent extract of $K$. reticulata was tested for in vivo efficacy. The methanol extract exhibited potent antioxidant activity compared to known antioxidant. In vivo studies on potent extract of $K$. reticulata demonstrated dose dependent reduction in hepatic malondialdehyde (330.70, 279.40 and $383.79 \mu \mathrm{Mmg}^{-1}$ protein) with simultaneous improvement in hepatic glutathione (7.03, 18.16 and $6.88 \mu$ gmg-1 protein) and catalase levels (678.10, 787.00 and $522.00 \mu \mathrm{gmg}^{-1}$ protein) respectively for $50,100 \mathrm{mgkg}^{-}$ ${ }^{1}$ dose and control) compared to control group. Due to its natural origin and potent free radical scavenging ability $K$. reticulata could be used as a potential preventive intervention for free radical mediated diseases ${ }^{21}$.

\section{Antiplasmodial activity}

Antiplasmodial of $K$. reticulata medicinal plants were extracted and tested for in vitro antiplasmodial activity against chloroquine-sensitive (K67) and chloroquineresistant (ENT36) strains of Plasmodium falciparum. Out of 16 extracts, 12 were active against ENT36 strain while seven were active against K67 strain, that is, IC50 < or = 50 micrograms $/ \mathrm{ml}$. The most active extracts on both strains were those of leaves of $K$. reticulata with IC50 < or $=10$ micrograms $/ \mathrm{ml}$. The stem barks of Terminalia spinosa Engl. (Combretaceae) and the stems of Dissotis brazzae Cogn. (Melastomataceae) had IC50 < or $=10$ micrograms/ml for strains K67 and ENT36, respectively. A phytochemical analysis of these plants revealed the presence of different classes of primary and secondary metabolites $^{22}$.

\section{Antinociceptive activity}

$K$. reticulata is used in folk medicinal practices of Bangladesh as an antinociceptive (reducing sensitivity to painful stimuli). The study was to investigate the 
antinociceptive activity of methanolic leaf extract of $K$. reticulata in Swiss albino mice. A model of acetic acidinduced gastric pain in mice was utilized to determine the antinociceptive effects. In writhing assays induced by acetic acid, the methanolic leaf extract showed significant inhibition compared to control. The maximum writhing inhibition $(39.1 \%)$ was found at a dose of 200 $\mathrm{mg}$ extract/kg body weight which, however, was lesser than that of the antinociceptive drug, aspirin (50.4\%), when used at a dose of $200 \mathrm{mg} / \mathrm{kg}$ body weight. Maximum tolerance (35.0\%) was showed at $400 \mathrm{mg}$ extract $/ \mathrm{kg}$ body weight, compared to that of the standard drug, glibenclamide at $10 \mathrm{mg} / \mathrm{kg}$ body weight $(57.8 \%)$. The methanol extract of $K$. reticulata leaves had beneficial effects as a pain reliever which validates the use of the plant in Bangladesh folk medicinal practices as a treatment for pain ${ }^{14}$.

\section{Analgesic activity}

The petroleum ether, ethyl acetate, and methanol extracts of $K$. reticulata were chosen for pharmacological screening. In the acetic acid-induced writhing test, the ethyl acetate extract in doses of 150 and $300 \mathrm{mg} / \mathrm{kg}$ showed 51.23 and $65.12 \%$ inhibition of writhing, respectively. A significant elongation of tail-flick time was evident both in the ethyl acetate and the methanol extracts $(42.38$ and $60.49 \%$ ) only at the $300 \mathrm{mg} / \mathrm{kg}$ dose level. The extracts of $K$. reticulata possess significant shows analgesic properties ${ }^{\mathbf{2 3}}$.

\section{Antiviral activity}

$K$. reticulata is a reputed medicinal plant used in Bangladesh and India for the treatment of gastric complaints including colic, constipation etc. The study was to evaluate the antiviral activity of this plant against hepatitis B virus (HBV) using HBsAg positive serum sample from hepatitis B virus infected patients. Two semi-purified organic fractions designated as PR1 and PR2 of the fat free ethanolic extract were tested at both lower and higher concentrations $(20 \mathrm{mg} / \mathrm{ml}$ and 40 $\mathrm{mg} / \mathrm{ml}$ respectively) for their anti hepatitis $\mathrm{B}$ virus surface antigen (anti-HBsAg) activity using an in vitro system by Reverse Passive Haemagglutination (R-PHA) method. SERRODIA-Anti-HBsAg- Diagnostic kit was used for detection of Anti-HBsAg antibody. Both fractions showed anti-HBsAg activity. But it was found the fractions have little inhibitory action on HBsAg at lower concentration whereas at the higher concentration they have prominent inhibitory action on the antigen. To the best of our knowledge this is the first report of the antiviral activity of $K$. reticulata against HBV. The AntiHBsAg activity observed by the fractions may be due to the binding of the agents with the antibody binding sites present on HBsAg. Thus the fractions might be the potential sources of the active principles responsible for antiviral activity ${ }^{24}$.

\section{Anti-inflammatory activities}

The present study pharmacognostic evaluation and antiinflammatory activity of $K$. reticulata fruit. The hydroalcoholic extract of ripe fruits and petroleum ether, ethyl acetate, and methanolic extracts of aerial parts was also screened for anti-inflammatory activity by carrageenan induced left hind paw oedema in rat at doses of $200 \mathrm{mg} / \mathrm{kg}$ and $400 \mathrm{mg} / \mathrm{kg}$, orally ${ }^{\mathbf{2 3 , 2 5}}$. In recently have worked on root part of this plant showed well potential effect of anti-inflammatory activities by Soni et $a l^{\mathbf{2 6}}$.

\section{Insectisidal activity}

Chemical constituents as well as insecticidal activity of the crude methanol extract from the leaves of $K$. reticulata. were investigated. $\left(5 R^{*}, 6 R^{*}\right)-4$, Dimethoxycarbonyl-5-[2',3',4'-trihydroxy-6'-

(methoxycarbonyl) phenyl]-5,6-dihydro- $2 H$ pyran-2-one along with 3,4,3'-tri-O-methylellagic acid, and methyl gallate were isolated from the dichloromethane extract. Determination of their structures was based on spectroscopic analysis. Compound 1 possessed a very weak insecticidal activity against Spodoptera frugiperda (Sf9) with an IC50 value of $27.27 \mu \mathrm{g} / \mathrm{mL}^{27}$.

\section{Hepatoprotective activities}

Two partially purified organic fractions designated by PR1 and PR2 of the fat free ethanol $(95 \%)$ extract of aerial parts of $K$. reticulata were tested for the hepatoprotective activity in rats against $\mathrm{CCl}$-induced liver damage. The rats receiving the fractions showed promising hepatoprotective activity as evident from significant changes of pentobarbital-induced sleeping time, changes in serum levels of sGPT, sGOT, sALP and bilirubin and also from histopathological changes as compared to CCl4-intoxicated rats $^{28}$. In other hand the ethanolic $(95 \%)$ roots extract of this plant have also reported hepatoprotective activity by paracetamol induced hepatotoxicity in wistar rat. Wistar rats of either sex were divided into six groups with six in each group. Group 1-Normal control: The animals were maintained under normal control, which were given $0.5 \%$ Tween 80 used as vehicle. Group 2-Induction of hepatotoxicity: The animals received paracetamol $(2 \mathrm{gm} / \mathrm{kg}$, p.o. $)$ every $72 \mathrm{~h}$ for 7 days. Group 3: The animals were treated with Silymarin $(100 \mathrm{mg} / \mathrm{kg}$, p.o $)$ which served as standard. Groups 4 to 6: Animals received ethanolic root extract of K. reticulata (EEKR) at $(100,200 \& 300 \mathrm{mg} / \mathrm{kg}$, p.o. $)$ everyday for 7 days. Groups 3 to 6 were intoxicated with paracetamol $(2 \mathrm{gm} / \mathrm{kg}$, p.o. $) 1 \mathrm{~h}$ before the administration of extract or Silymarin for 7 days. Histopathological findings, different hepatic biochemical parameters viz. Serum glutamic-oxaloacetic transaminase (sGOT), serum glutamic pyruvic transaminase (sGPT), serum alkaline Phosphatase (sALP), Total bilirubin, Total albumin \& blood urea were evaluated to investigate the hepatoprotective activity. Paracetamol induced a significant rise in sGOT, sGPT, sALP, Total bilirubin, Total albumin, \& blood urea estimation. Administration of $300 \mathrm{mg} / \mathrm{kg}$, p.o. ethanolic root extract of K. reticulata less effectively reduced these pathological damages caused by paracetamol intoxication. The ethanolic root extract of $K$. reticulata also promoted the body weight in Wistar rats. Histopathological changes of the liver were compared with the normal control. The ethanolic roots extract at dose of $300 \mathrm{mg} / \mathrm{kg}$, p.o. of $K$. reticulata have significant effect on hepatoprotective activity against paracetamol induced hepatotoxicity in Wistar rats ${ }^{29}$. 


\section{CONCLUSION}

The goal of ethnopharmacological studies on medicinal plants should not be restricted to find new prototype pure compounds as drugs. Active extracts, fractions or mixture of fractions/extracts may prove very effective drugs. Plant drugs (combinations or individual drug) for liver diseases should possess sufficient efficacy to cure severe liver diseases caused by toxic chemicals, viruses (Hepatitis B, Hepatitis C, etc.), excess alcohol intake, etc. A single drug cannot be effective against all types of severe liver diseases. Effective formulations have to be developed using indigenous medicinal plants, with proper pharmacological experiments and clinical trials. The manufacture of plant products should be governed by standards of safety and efficacy.

\section{REFERENCES}

[1] Soni RK, Irchhaiya R, Dixit V, Alok S. Paederia foetida Linn: Phytochemistry, pharmacological and traditional uses. Int $J$ Pharm Sci Res 2013; 4(12): 4525-4530.

[2] Soni RK, Chandra A, Irchhaiya R, Dixit V, Singh N, Singh H. Kirganelia reticulata (Poir.) Baill.-A review on its botany, ethnobotany, phytochemistry and pharmacology. J Drug Del Thera 2013; 3(6): 168-184.

[3] Soni RK, Dixit V, Irchhaiya R, Singh H. A review update on Shorea robusta Gaertn f. (Sal). J Drug Del Thera 2013; 3(6): 127-132.

[4] Khan MR, Ndaalio G, Nkunya MHH, Wevers H. Studies on the rationale of African traditional medicines. Part $2^{\text {nd }}$ : Preliminary screening of medicinal plants for anti-gonoccoci activity. Pakistan J Sci Indus Res 1978; 27: 189-192.

[5] Khan MR, Ndaalio G, Nkunya MHH, Wevers H. Studies on African medicinal plants. Part $1^{\text {st }}$ : Preliminary screening of medicinal plants for antibacterial activity. Planta Med Suppl 1980; 40: 91-97.

[6] Sawhney AN, Khan MR, Ndaalio G, Nkunya MHH, Wevers H. Studies on the rationale of African traditional medicine. Part $3^{\text {rd }}$ : Preliminary screening of medicinal plants for antifungal activity. Pakistan J Sci Indus Res 1978; 27: 193-196.

[7] Joshi KC, Singh P, Mehra A. Crystalline components of the roots of Phyllanthus reticulatus. J Indian chemical Soc 1981; 58: 102-103.

[8] Avirutnan W, Pongpan A. The antibacterial activity of some Thai flowers and plants. Mahiodol Univ J Pharma Sci 1983; 10: 81-86.

[9] Arbain D, Cannon JRA, Kartawinata K, Djamal R, Bustari A et al. Survey of some West Sumatran plants for alkaloids. Economic Botany 1989; 43: 73-78.

[10] Rizk AFM. The chemical constituents and economics plants of the euphorbiaceae. Botanical J Linnean Soc 1987; 94: 293-326.

[11] Bhakuni DS, Dhar ML, Dharma MN, Dhawan BN, Gupta B, Srimali RC. Screening of Indian plants for biological activity.

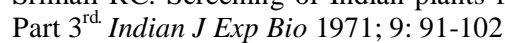

[12] Kumar S, Kumar D, Deshmukh RR, Lokhande PD, More SN, Rangari VD. Antidiabetic potential of Phyllanthus reticulatus in alloxan-induced diabetic mice. Fitoterpia 2008; 79: 21-23.

[13] Kumar S, Kumar D, Deshmukh RR, Rangari VD. Hypoglycemic activity of roots of Phyllanthus reticulatus in alloxan induced diabetic mice. Int J Plant Sci 2007; 2(1): 184187.

[14] Rahmatullah M, Khokon CG, Mamun AA, Hossain MT, Ahmed S, Rahman MA, Eva B, Rahman S, Chowdhury MH. A pharmacological study on antinociceptive and antihyperglycemic effects of methanol extract of leaves of Phyllanthus reticulatus Poir. in Swiss albino mice. Adv Nat Appl Sci 2010; 4(3): 229-232.

[15] Sankannavar SH, Patil CG. In Vitro studies on diversity of antibacterial activity in some species of Phyllanthus for human pathogenic bacteria. Asian J Exp Biol 2012; 3(3): 607-612.
From the above review on Kirganelia reticulata, we can conclude how important the medicinal effect plant. There is coexistence between some of traditional usages of this plant like applying on inflammation, Liver protective etc and experimentally observed effect of the extracts as mentioned above but various biological studies available on components of this plant.

CONFLICT OF INTEREST: We declare that we have no conflict of interest.

\section{ACKNOWLEDGEMENTS}

The author is very thankful with to Dr. Raghuveer Irchhaiya and Vihangesh Dixit for valuable guidance, suggestions and advice during the preparation of this manuscript, specially thanks to NBRI Lucknow for identified and authenticated the plant.

[16] Shruthi SD, Rai PS, Ramachandra YL. In vitro antibacterial activity of Kirganelia reticulates Baill. Against methicillinresistant Staphylococcus aureus. Pharmacophore 2010; 1(2): 123-131.

[17] Shruthi SD, Ramachandra YL, Padmalatha RS, Shetty VA. Antibacterial potential of leaf extracts from Kirganelia reticulata Baill. Int J Pharma Res develop 2010; 2(6): 1-7.

[18] Maruthappana V, Shreeb KS. In vitro and in vivo antioxidant activity of Phyllanthus reticulatus. Drug Invention Today 2010; 2(6): 303-307.

[19] Aswatha Ram HN, Shreedhara CS, Gajera FP. Zanwar SB. In Vitro Free Radical Scavenging Potential of Methanol Extract of Entire Plant of Phyllanthus Reticulatus Poir., Pharmacologyonline 2008; 2: 440-451.

[20] Shruthi SD, Rajeswari A, Govardhana Raju K, Pavani A, Vedamurthy AB, Ramachandra YL. Phytochemical and antioxidant analysis of leaf extract from Kirganelia reticulata. Int J Pharm Pharm Sci 2012; 4(3): 608-612.

[21] Maruthappan V, Shree KS. A report on the antioxidant activity of the powder of the entire plant of Phyllanthus reticulatus Poir. Int J Green Pharm 2010; 265-269.

[22] Omulokoli E, Khan B, Chhabra SC. Antiplasmodial activity of four Kenyan medicinal plants. J Ethnopharmacol 1997; 56: 133-137.

[23] Saha A, Masud MA, Bachar SC, Kundu JK, Datta BK, Nahar L, Sarker S. The Analgesic and Anti-Inflammatory Activities of the Extracts of Phyllanthus reticulatus. Pharma Biol 2007; 45(5): 355-359.

[24] Das BK, Shohel M, Pavel AM, Bhattacharjee R, Das B, Yasmin T et al. Anti Hepatitis B Viral Activity of Phyllanthus reticulatus. Bangladesh Pharma J 2011; 14(1): 11-14.

[25] Kumar S, Sharma S, Kumar D, Kumar T, Arya R, Kumar K. Pharmacognostic study and anti-inflammatory activity of Phyllanthus reticulatus Poir. fruit. Asian Pac J Trop Dis 2012; S332-S335.

[26] Soni RK, Irchhaiya R, Dixit V, Bhat ZA, Wani HA, Najar AH. Anti-inflammatory activity of Kirganelia reticulata (Poir).Baill. root by carrageenan-induced rat paw oedema model. Int J Pharm Pharm Sci 2014; 6(1): 520-523

[27] Pojchaijongdee N, Sotanaphun U, Limsirichaikul S, Poobrasert O. Geraniinic acid derivative from the leaves of Phyllanthus reticulatus. Pharma Biol 2010; 48(7): 740-744.

[28] Das BK, Bepary S, Bidyut K. Datta AK, Chowdhary A, Ali MS, Rouf ASS. Hepatoprotective activity of Phyllanthus reticulatus. Pak J Pharm Sci. 2008; 21(4): 333-337.

[29] Soni RK, Irchhaiya R, Dixit V, Bhat ZA, Wani HA, Najar AH. Hepatoprotective activity of Kirganelia reticulata Poir. (Baill) root against paracetamol induced Hepato-toxicity in wistar rats. Int J Pharm Pharm Sci 2014; 6(2): 273-278. 